\title{
A Comparative Evaluation of Adsoprtion Isotherm in Clay- Dominated Shale
}

\author{
H. Bashir \\ School of Computing, Science \& Engineering, University of Salford, Manchester M5 4WT, UK \\ Y. Wang \\ School of Computing, Science \& Engineering, University of Salford, Manchester M5 4WT, UK \\ M. Burby \\ School of Computing, Science \& Engineering, University of Salford, Manchester M5 4WT, UK
}

\begin{abstract}
One of the bottlenecks of production in an unconventional resource like shale is the issue of adsorbed gas. The process of quantifying adsorption is through experimental methods and the results fit to an isotherm to determine the total adsorbed gas. In this study, we fit four methane adsorption experimental datasets on mineral dominated shale selected from literature of inorganic components of shale to the Langmuir, Freundlich, Sips or Freundlich-Langmuir, Redlich-Paterson isotherm to determine the best fit. In order to determine the goodness of fit to isotherm model, we used three statistical criterions which are; the correlation coefficient $\left(r^{2}\right)$, standard errors (S.E.) and residual plot for each parameter to evaluate the data. The Langmuir isotherm is usually adopted as the ideal isotherm which describes adsorption capacity in shale reservoir. It is shown in this work that compared to the Langmuir, Freundlich and Sips or Freundlich-Langmuir, the Redlich-Paterson isotherm describes adsorption of clay rich shale more accurately. The modelling results showed that Redlich-Paterson model fits experimental data better than the other three isotherms, with relatively higher $r^{2}$ values and smaller S.E.
\end{abstract}

Keywords: Adsorption isotherm, methane adsorption, clay rich shale

\section{INTRODUCTION}

Gas stored in unconventional reserves like shale consist of gas adsorbed by organic matter and according to many authors (Lu et al, 1994, 1995; Alnoaimi et al, 2013); Ji et al, 2012) adsorbed in clay. The monolayer Langmuir isotherm has been shown to fit methane gas adsorption data accurately for organic matter, clay and kerogen (Glorioso et al, 2012). However, researchers of shale adsorption have found other isotherms capable of accurately fitting experimental data. This had led to journals, where different isotherms types are compared to determine which fits best to different shale types. For instance, it has been proved that organic shale and clay minerals are best described by the monolayer Langmuir at low pressure, but comparative studies have shown that other factors such as experimental pressure, temperature and composition of sample can change experimental data. Furthermore, multi-layer adsorption has been observed with data fitting the BET and BiLangmuir isotherms. For the most part, Adsorption in clay minerals have been shown to be monolayer with researchers concluding that Langmuir gives the best fit to experimental data. Such studies on clay dominated samples include; Ji et al, (2012) who reports that the Langmuir isotherm described clay mineral dominated adsorption experimental data adequately, furthermore a good fit was found for pure clay samples (Heller \& Zoback, 2014) while for organic shale samples; Mengal et al, 2011 adopted data from previous literature (Wang et al, 2009; Jacobi et al, 2007; Adam et al, 2008) and concluded that a Langmuir fit is ideal for experimental data. Most researchers (Zhang et al, 2012; Guo et al, 2014) generally that adsorption in shale is monolayer.

However, this does not necessarily mean only the monolayer Langmuir fits adsorption data. For china shale, Li et al, 2015 used three isotherms types (Langmuir, Multi-layer BET and DA) isotherm to fit data. They observed that even though Langmuir can be used to adequately describe shale adsorption, the DA fit was the best match, with the BET isotherm giving more accurate result. In another investigation (Lu et al, 1995) used two isotherm types Langmuir and Bi-Langmuir isotherm to fit experimental data of Devonian shale. They discovered that in terms of temperature effects, the Bi-Langmuir adequately describe adsorption at different temperature while the strength of the Langmuir isotherm was at describing the effect of pressure at a fixed temperature. It can be concluded then that since temperature might affect sorption in shale, the Langmuir might not account for this inconsistencies. For shale like the Marcellus, investigation (Yu et al, 2014) showed that at very high pressure, multilayer adsorption occurs and isotherms like BET, describes the adsorption capacity. 
However, there are variations of the Langmuir which have been updated to account for different phenomena such as a three parameter isotherm (Gasparik et al, 2012) which adequately describes gas adsorption capacity.

In this study, we fit four methane adsorption experimental datasets on shale from literature of inorganic components of shale to the Langmuir, Freundlich, Redlich-Paterson and Sips or Freundlich-Langmuir isotherm to determine the best fit. In order to determine the best fit isotherm model, we used three criterions which are; the correlation coefficient $\left(\mathrm{r}^{2}\right)$, standard errors (S.E.) and residual plot for each parameter to evaluate the data. A number of studies have been conducted on organic shale and kerogen and fit to two or more isotherms to determine the best fit, but to our knowledge this is the first study which has been carried out on clay mineral dominated shale.

\section{THEORY AND METHODS}

Using datasets from literature, the appropriate model describing sorption isotherm data in shale was determined. Five isotherm models, including two-parameter and three-parameter equations, were used to evaluate the fitting ability of the models. Datasets from literature used in Isotherm fitting are listed in the table below:

Table - 1 Source of isotherm fitting data

\begin{tabular}{|c|c|c|c|c|}
\hline Reference & Shale Type & source & Pressure & Temperature \\
\hline Ji et al (2012) & Clay minerals & Data & $0-14 \mathrm{MPa}$ & $35.4^{0} \mathrm{C}$ \\
\hline
\end{tabular}

\section{A. Theoretical modelling of adsorption Isotherms}

In recent years, a large number of models have been formulated (Foo \& Hammed, 2009). These models are used to fit to raw experimental data in order to quantify the adsorbed volume at equilibrium. The next section presents a review on isotherms used in this thesis for fitting raw experimental data:

\section{Langmuir Isotherm}

The Langmuir isotherm is an empirical model originally developed to describe one layer or monolayer adsorption. It is based on ideal assumption, which are; 1) Adsorbed layer is one molecule in thickness, with adsorption can only occur at a finite (fixed) number of definite localized sites; 2) That are identical and equivalent, with no lateral interaction and steric hindrance between the adsorbed molecules, even on adjacent sites (Foo \& Hammed, 2009) and can be expressed as:

$$
\mathrm{V}=\mathrm{V}_{\mathrm{L}} \mathrm{P} / \mathrm{R}_{\mathrm{L}}+\mathrm{P}
$$

Where, $\mathrm{V}$ is adsorption equilibrium capacity (Scf/ton); VL is the Langmuir volume and PL is the Langmuir Pressure (MPa). This model is the most widely used to describe shale adsorption dynamics, but it due to the it not adequately describing multi-layer adsorption or temperature differentials other isotherms where developed.

\section{Freundlich Isotherm}

The first mathematical fit to an isotherm was published by Freundlich and Kuster (1894). It is an empirical equation which is applied in the low to intermediate pressure ranges and can be applied to multi-layer adsorption, it can be expressed as:

$$
\frac{\mathrm{x}}{\mathrm{m}}=\mathrm{kP} \mathrm{P}^{\frac{1}{\mathrm{n}}}
$$

Where $\mathrm{x}$ : the amount of adsorbed, g, m: mass of adsorbent, g, P: pressure of adsorbate (MPa), k and n: are empirical constant (changing with temperature).

\section{Redlich-Paterson Isotherm}


Redlich-Peterson isotherm is an isotherm featuring both Langmuir and Freundlich isotherms, it is a hybrid developed Jossens and workers, who modified the three parameter equation first developed by Redlich and Peterson (1959). At low pressure, it describes the Langmuir isotherm at high pressure it becomes the Freundlich isotherm (Ho et al, 2001). It can be expressed as:

$$
q_{e}=K_{R} C_{e} / 1+a_{R} C_{e} g
$$

Where, $\mathrm{K}_{\mathrm{R}}, \mathrm{a}_{\mathrm{R}}$ and $\mathrm{g}$ are the Redlich-Peterson isotherm constants.

\section{Sips or Langmuir- Freundlich isotherm}

Sips isotherm is an equation developed by Sips in 1948, which combines both the Langmuir and Freundlich expressions. It is usually expressed as:

$q_{e}=\mathrm{K}_{s} C_{e}^{B s} / 1+\alpha_{s} C_{e}{ }^{B s}$

\section{B. Statistical analysis}

All the model parameters were evaluated by both non-linear regression using Mat lab curve fitting software.

\section{The sum of squares due to error (SSE)}

This statistic measures the total deviation of the response values from the fit to the response values. It is also called the summed square of residuals and is usually labelled as SSE.

$S S E=\sum_{i=1}^{n} \omega_{i}\left(y_{i}-y_{i}\right)^{2}$

A value closer to 0 indicates that the model has a smaller random error component, and that the fit will be more useful for prediction. It is used to measure the goodness-of-fit, this measures the deviation of the responses from the fitted values of the responses. A value closer to 0 indicates a better fit.

\section{II. $\quad$ Coefficient of multiple determination $\left(R^{2}\right)$}

This statistic measures how successful the fit is in explaining the variation of the data. Put another way, Rsquare is the square of the correlation between the response values and the predicted response values. It is also called the square of the multiple correlation coefficient and the coefficient of multiple determination. R-square is defined as the ratio of the sum of squares of the regression (SSR) and the total sum of squares (SST). SSR is defined as

$$
S S R=\sum_{i=1}^{n} w_{i}\left(y_{i}-y\right)^{2}
$$

R-square can take on any value between 0 and 1, with a value closer to 1 indicating that a greater proportion of variance is accounted for by the model. For example, an R-square value of 0.8234 means that the fit explains $82.34 \%$ of the total variation in the data about the average.

$S S T=\sum_{i=1}^{n} w_{i}\left(y_{i}-y\right)^{2}$

If you increase the number of fitted coefficients in your model, R-square will increase although the fit may not improve in a practical sense. To avoid this situation, you should use the degrees of freedom adjusted R-square statistic described below.

$$
\mathrm{SST}=\mathrm{SSR}+\mathrm{SSE}
$$

$$
\text { R-Square }=\frac{S S R}{S S T}=1-\frac{S S E}{S S T}
$$

Note that it is possible to get a negative R-square for equations that do not contain a constant term. Because Rsquare is defined as the proportion of variance explained by the fit, if the fit is actually worse than just fitting a horizontal line then R-square is negative. In this case, R-square cannot be interpreted as the square of a correlation. Such situations indicate that a constant term should be added to the model. This parameter measures 
how successful the fit is in explaining the variation of the data. A value closer to 1 indicates a better fit was also used to determine the best-fitting isotherm to the experimental data.

\section{III. $\quad$ The root mean squared error (RMSE)}

This statistic is also known as the fit standard error and the standard error of the regression. It is an estimate of the standard deviation of the random component in the data, and is defined as

$$
\mathrm{RMSE}=\mathrm{S}=\sqrt{M S E} \quad 8
$$

where MSE is the mean square error or the residual mean square

$$
\mathrm{MSE}=\frac{S S E}{V}
$$

The residual degrees of freedom can be defined as the number of response values $\mathrm{n}$ minus the number of fitted coefficients $m$ estimated from the response values.

$$
\mathrm{V}=\mathrm{n}-\mathrm{m}
$$

$\mathrm{v}$ indicates the number of independent pieces of information involving the $\mathrm{n}$ data points that are required to calculate the sum of squares. Just as with SSE, an MSE value closer to 0 indicates a fit that is more useful for prediction. This parameter indicates that a value closer to 0 indicates a better fit.

\section{RESULT \& DISCUSSION}

The experimental data set used in fitting four isotherm types (Freundlich, Langmuir, Redlich- Paterson and Sips) were collected from the work of $\mathrm{Ji}$ et al, 2012 also the experimental Langmuir constant from the experimental data are presented along with fitting data from our study. Three criterion (SSE, RMSE, $\mathrm{R}^{2}$ and Residual Plots) were used to determine the goodness of fit for each clay type. Figures showing isotherm fitting and residual plots were attached as appendix. For pure clay minerals, table 1 shows the values of corresponding isotherm parameters, the criterion used in fitting data for clay dominated shale samples. Result from fitting as presented in table 1 shows a high value of $\mathrm{r}^{2}$ (coefficient of multiple determination) for fitting with experimental data for the Redlich-Paterson model ( $2>0.9983)$, followed close by the Langmuir model with an $\mathrm{r}^{2}$ value greater than

\begin{tabular}{|c|c|c|c|c|}
\hline $\begin{array}{l}\text { Isotherm model / } \\
\text { Error Function }\end{array}$ & Montmorillonite & illite & Kaolinite & chlorite \\
\hline $\begin{array}{c}\text { Langmuir (Ji et } \\
\text { al, 2013) } \\
\text { VL (mmol/g } \\
\text { rock) } \\
\text { PL (1/MPa) }\end{array}$ & $\begin{array}{l}0.380 \\
0.451\end{array}$ & $\begin{array}{l}0.079 \\
0.211\end{array}$ & $\begin{array}{l}0.120 \\
0.179\end{array}$ & $\begin{array}{l}0.103 \\
0.165\end{array}$ \\
\hline $\begin{array}{c}\text { Freundlich } \\
\mathrm{K}_{\mathrm{F}} \\
\mathrm{N}\end{array}$ & $\begin{array}{c}0.13 \\
0.3861\end{array}$ & $\begin{array}{c}0.01682 \\
0.5143\end{array}$ & $\begin{array}{c}0.02099 \\
0.5959\end{array}$ & $\begin{array}{c}0.01725 \\
0.5808\end{array}$ \\
\hline Goodness of Fit & $\begin{array}{c}\text { SSE: } 0.004769 \\
\text { R-square: } 0.02082 \\
\text { RMSE: } 0.9331\end{array}$ & $\begin{array}{c}0.0001413 \\
0.003297 \\
0.9591\end{array}$ & $\begin{array}{c}0.0002148 \\
0.004231 \\
0.9725\end{array}$ & $\begin{array}{c}0.000158 \\
0.003975 \\
0.9625\end{array}$ \\
\hline $\begin{array}{l}\text { Langmuir } \\
\text { VL } \\
\text { PL }\end{array}$ & $\begin{array}{l}0.3813 \\
0.4094\end{array}$ & $\begin{array}{c}0.08241 \\
0.1944\end{array}$ & $\begin{array}{c}0.01399 \\
0.1393\end{array}$ & $\begin{array}{l}0.1053 \\
0.1568\end{array}$ \\
\hline Goodness of Fit & SSE:0.0004784 & $2.466 \mathrm{e}-005$ & $3.507 \mathrm{e}-005$ & $3.436 \mathrm{e}-005$ \\
\hline
\end{tabular}
0.9918 .

Table - 2 Statistical indicators and model parameters for clay dominated shale samples: 


\begin{tabular}{|c|c|c|c|c|}
\hline & R-square:0.006595 & 0.001377 & 0.001709 & 0.001854 \\
& RMSE: 0.9933 & 0.9929 & 0.9955 & 0.9918 \\
\hline Redlich & & & & \\
Patterson & 0.6348 & 0.2689 & 0.5803 & 0.6407 \\
$\mathrm{~K}_{\mathrm{R}}$ & 1.199 & 1.439 & 1.534 & 1.696 \\
$\mathrm{a}_{\mathrm{R}}$ & 5.215 & 22.1 & 37.59 & 51.62 \\
$\mathrm{~g}$ & $\mathrm{NSE}: 0.0001186$ & $5.034 \mathrm{e}-006$ & $2.744 \mathrm{e}-006$ & $1.663 \mathrm{e}-006$ \\
\hline \multirow{3}{*}{ Goodness of Fit } & R-square:0.003444 & 0.0006477 & 0.0004994 & 0.0004298 \\
& RMSE:0.9983 & 0.9985 & 0.9996 & 0.9996 \\
\hline Sips & & & & \\
Ks & 22.9 & 3.865 & 46.67 & 22.5 \\
Bs & 0.3862 & 0.5143 & 0.5958 & 0.5812 \\
$\alpha_{s}$ & -26.32 & -3.931 & -47.68 & -22.89 \\
\hline & & & & \\
Goodness of Fit & R-square: 0.02184 & 0.003432 & 0.004419 & 0.00419 \\
& RMSE:0.9331 & 0.9591 & 0.9725 & 0.9625 \\
& & & & \\
\hline
\end{tabular}

The other models showed lower fit with values greater than 0.9331 for the Freundlich and sips model respectively. The values obtained from the SSE, shows that the Sips models has the highest values that is further from zero, followed by Freundlich, Langmuir and the Redlich-Paterson. A comparison of the fitting constant compared to experimental data shows that the Langmuir fitting values are closer to the values obtained in literature ( $\mathrm{Ji}$ et al, 2012) for adsorption capacity (i.e. the Langmuir volume (VL) and Langmuir pressure (PL). The result shows that the Sips model does not describe shale adsorption and should be avoided, by comparison, the order of the isotherm best fits for clay dominated samples are Redlich-Paterson > Langmuir $>$ Freundlich.

\section{CONCLUSION}

Experimental adsorption data of four clay dominated shale taken from literature (Ji et al, 2012) were fitted to isotherm models by non-linear regression using Mat lab R2016A software. The results showed that the Redlich Paterson model could fit the data better than the Langmuir, Freundlich or Sips or Freundlich- Langmuir models, and the determined parameters were acceptable. The result shows that the Sips model does not describe shale adsorption and should be avoided, by comparison, the order of the isotherm best fits for clay dominated samples are Redlich-Paterson $>$ Langmuir $>$ Freundlich. It can be concluded that the Redlich-Paterson has the best fit but however the adsorption capacity is best described by the Langmuir Isotherm.

\section{REFERENCES}

[1] Foo, K. Y., \& Hameed, B. H. (2010). Insights into the modeling of adsorption isotherm systems. Chemical Engineering Journal, 156(1), 2-10. doi:10.1016/j.cej.2009.09.013

[2] Gasparik, M., Ghanizadeh, A., Bertier, P., Gensterblum, Y., Bouw, S., \& Krooss, B. M. (2012). High-pressure methane sorption isotherms of black shales from the Netherlands. Energy and Fuels, 26(8), 4995-5004. doi:10.1021/ef300405g

[3] Glorioso, J. C., \& Rattia, A. (2012). Unconventional Reservoirs : Basic Petrophysical Concepts for Shale Gas. Spe 153004, (March), 1-38. doi:10.2118/153004-MS

[4] Heller, R., \& Zoback, M. (2014). Adsorption of methane and carbon dioxide on gas shale and pure mineral samples. Journal of Unconventional Oil and Gas Resources, 8(C), 14-24. doi:10.1016/j.juogr.2014.06.001

[5] Ji, L., Zhang, T., Milliken, K. L., Qu, J., \& Zhang, X. (2012). Experimental investigation of main controls to methane adsorption in clay-rich rocks. Applied Geochemistry, 27(12), 2533-2545. doi:10.1016/j.apgeochem.2012.08.027

[6] Li, T., \& Wu, C. (2015). Research on the abnormal isothermal adsorption of shale. Energy and Fuels, 29(2), 634-640. doi:10.1021/ef5024274

[7] Lu et al, 1993. (1993). Adsorption Measurments in Devonian Shale.

[8] Lu, X., Li, F., \& Watson, A. (1995). Adsorption studies of natural gas storage in Devonian shales. SPE Formation Evaluation, (June). Retrieved from https://www.onepetro.org/journal-paper/SPE-26632-PA

[9] Mengal, S. a, Wattenbarger, R. a, \& Texas, a. (2011). SPE 141085 Accounting For Adsorbed Gas in Shale Gas Reservoirs, (September), 25-28.

[10] Wang, S., Song, Z., Cao, T., \& Song, X. (2013). The methane sorption capacity of Paleozoic shales from the Sichuan Basin, China. Marine and Petroleum Geology, 44, 112-119. doi:10.1016/j.marpetgeo.2013.03.007

[11] Yu, W., Sepehrnoori, K., \& Patzek, T. W. (2014). Evaluation of Gas Adsorption in Marcellus Shale Adsorption Model for Shale Gas Reservoirs, (October), 27-29.

[12] Zhang, T., Ellis, G. S., Ruppel, S. C., Milliken, K., \& Yang, R. (2012). Effect of organic-matter type and thermal maturity on methane adsorption in shale-gas systems. Organic Geochemistry, 47, 120-131. doi:10.1016/j.orggeochem.2012.03.012 